\title{
Experience of the neonatal intensive care unit of the National researchscience center for maternal and child health
}

\author{
Tamara Chuvakova ${ }^{1}$, Botakoz Abentaeva ${ }^{2}$, Raushan Kamieva ${ }^{2}$, Bibigul Charipova ${ }^{2}$, Gaukhar Temirbaeva ${ }^{2}$
}

${ }^{1}$ department of neonatology, National research center for maternal and child health of the corporate fund "UMC", Astana, Kazakhstan

2 the neonatal resuscitation and intensive care unit, National research center for maternal and child health of the corporate fund "UMC", Astana, Kazakhstan
J CLIN MED KAZ 2017; 3(45 SUPPL 3):145-149

Corresponding author: Чувакова Тамара Курмангалиевна, доктор медицинских наук, профессор, главный научный сотрудник ФКФ «UMC» ННЦМД, г. Астана, пр. Туран 32, 010000, моб. телефон

+7 701 9996880, электронный адрес: ch.tamara@mail.ru.

\section{ABSTRACT}

The article presents the work results of Neonatal Intensive Care Unit of National Research Center for Maternal and Child Health. The main goal of the unit is to increase the survival rate of sick newborns, including premature babies. In addition, to minimize the possible complications that lead to increase in the number of people disabled since childhood and impair their quality of life. Realization of this purpose became possible with the introduction of effective evidence-based medical care. As a result, for the period from 2008 to 2016, the survival rate of extremely low birth weight infants (500-999g) increased from $13 \%$ to $67 \%$ and very low body weight infants from $78 \%$ to $98 \%$ acordingly.

Key words: premature newborns, extremely low and very low birth weight, survival rate.

\section{ТҰЖЫРЫМДАМА}

АНА МЕН БАЛА ҰЛТТЫҚ ҒЫЛЫМИ ОРТАЛЫҒЫНЫН ЖАНА ТУҒАН НӘРЕСТЕЛЕР РЕАНИМАЦИЯСЫНЫН БӨЛІМШЕСІНІНТӘЖІРИБЕСІ Чувакова Т.К. ${ }^{1}$, Абентаева Б.А. ${ }^{2}$, Камиева Р.Т. ${ }^{2}$, Чарипова Б.Т. ${ }^{2}$, ТемирбаеваГ.Т. ${ }^{2}$

'Неонатология бөлімі, «UMC» корпоративтік қорының Ана мен бала ұлттық ғылыми орталығы, Астана, Қазақстан

${ }^{2}$ Нәрестелер реанимациясының бөлімшесі, «UMC» корпоративтік қорының Ана мен бала ұлттық ғылыми орталығы, Астана, Қазақстан

Макалада Ұлттық анамен бала ғылыми орталығының нәрестелерді қарқынды емдеу және жансақтау бөлімшесінің жұмыс нәтижесі көрсетілген. Жұмыстың негізгі мақсаты нәрестелердін оның ішінде шала туылған нәрестелердің өлім санын азайту және мүгедектік пен өмір сапасын төмендетуге әкеп соғатын ықтимал асқынуларды азайту. Көздеген мақсатқа бөлімшенің күнделіктіжұмыс барысына ғылыми-дәлелденген медицинаға негізделген медициналық көмек пен күтіп бағудын жаңа технологияларын енгізе отырып қол жеткізген. Салыстыра айтқанда 2008-2016жылдар аралығында эктрималды аз салмақпен (500-999г) шала туылған нәрестелердің аман қалу көрсеткіші 13\% дан 67\% өскен және өте аз салмақта дүниеге келген нәрестелердің аман қалу көрсеткіші 78\% дан 98\% артқан.

Маңызды сөздер: шала туылған нәрестелер, эктрималды аз және өте аз салмақта дүниеге келген нәрестелер, аман қалу көрсеткіші.

\section{PEЗЮME}

ОПЫТ РАБОТЫ ОТДЕЛЕНИЯ РЕАНИМАЦИИ И ИНТЕНСИВНОЙ ТЕРАПИИ НОВОРОЖДЕННЫХ НАЦИОНАЛЬНОГО НАУЧНОГО ЦЕНТРА МАТЕРИНСТВА И ДЕТСТВА

Чувакова Т.К. ${ }^{1}$, Абентаева Б.А. ${ }^{2}$, Камиева Р.Т. ${ }^{2}$, Чарипова Б.Т. ${ }^{2}$, Темирбаева Г.T. ${ }^{2}$

'Отдел неонатологии, Национальный научный центр материнства и детства корпоративного фонда «UMC», г. Астана, Казахстан

${ }^{2}$ Отделение реанимации новорожденных, Национальный научный центр материнства и детства корпоративного фонда «UMC», г. Астана, Казахстан

В статье представлены итоги работы отделения реанимации и интенсивной терапии новорожденных Национального научного центра материнства и детства. Основной целью работы отделения является повышение выживаемости больных новорожденных, в том числе недоношенных и минимизация реализации возможных осложнений, приводящих к повышению числа инвалидов с детства и нарушению качества их жизни. Выполнение поставленной цели стало возможным в связи с внедрением в практику отделения технологий ухода и медицинской помощи новорожденным, основанным на научно-доказательной медицине. В итоге за период с 2008 по 2016 гг выживаемость младенцев с экстремально низкой массой тела (500-999 г) повысилась с $13 \%$ до $67 \%$ и с очень низкой массой тела с $78 \%$ до $98 \%$.

Ключевые слова: недоношенные новорожденные, экстремально низкая и очень низкая масса тела при рождении, выживаемость. 


\section{Введение}

С января 2008 года, согласно распоряжению Премьерминистра РК, страна перешла на международные критерии живорождения и мертворождения, согласно которым в статистику включаются данные о плодах и новорожденных с гестационным возрастом от 22 недель и более,массой тела от 500 г и более. Успехи медицинской науки к концу XX века позволили разработать новые технологии выхаживания этого контингента новорожденных, новые методы диагностики, терапии и профилактики заболеваний, что позволило значительно повысить их выживаемость.

По данным экспертов ВО3 (2005 г) за последнее десятилетие 20-го столетия в экономически развитых странах летальность новорожденных с массой тела при рождении (МТР) от 1000 до 1500 г снизилась с 50\% до 5\% и с МТР от 500 до 999 г - с 90\% до 20\%. Этому способствовала правильная организация пренатального и постнатального ухода, позволившая определить доминирующие аспекты их выхаживания, к которым относятся: проведение антенатальной стероидной профилактики в случае преждевременных родов; антибактериальная терапия в родах с целью снижения патологической колонизацции родовых путей; раннее применение назального СРАР, и адекватный лечебно-охранительный режим.

Все эти основополагающие принципы были внедрены в работу отделения реанимации и интенсивной терапии новорожденных (ОРИТН) КФ “UМС”ННЦМД.

Основной целью работыОРИТН является повышение выживаемости больных новорожденных, в том числе недоношенных и минимизация реализации возможных осложнений, приводящих к повышению числа инвалидов с детства и нарушению качества их жизни.

Основные результатыработы ОРИТН. Важное значение, при выхаживании больных новорожденных инедоношенных детей, придается современным методам ухода, включающим соблюдение охранительного режима и раннее начало грудного вскармливания, а при его невозможности - кормление сцеженным материнским грудным молоком любым альтернативным методом (зондом, чашкой, шприцем и др.). При проведении парентерального питания и инфузионной терапии применяются глубокие венозные линии.

Охранительный режим включает не только соблюдение должного температурного режима, минимизации болевых процедур и снижении воздействий шума, прямых лучей света, придания ребенку удобного положения в кювезе,/кроватке, но и обязательныйматеринский уход и поддержание инфекционной безопасности.

Внедряемые в работу отделения технологии по профилактике и лечению критических состояний и заболеваний неонатального периода, постоянно обновляются, согласно рекомендациям,опубликованным в журналах дальнего зарубежья,материалах международных конгрессов и симпозиумов. Все эти рекомендации включены в разработанные сотрудниками отделения клинические протоколы по уходу и лечению критических состояний и болезней у новорожденных.

При лечении гемолитической болезни новорожденного (ГБН) широко используется введение внутривенного иммуноглобулина актогама, действие которого направлено на предотвращение гемолиза эритроцитов. Назначается иммуноглобулин в первые 2 часа после рождения, что возможно только при антенатальной постановке диагноза ГБН. Такая терапия способствовали снижению частоты проведения операций заменного переливания крови и тяжелых осложнений, которые по данным зарубежных авторов встречаются в $12 \%$ случаев [1].

Современная техническая модернизация ОРИТН позволила внедрить в практику все возможные режимы вентиляции легких, в том числевысокочастотную осциллятору вентиляцию, что особенно важно при лечении недоношенных с тяжелыми респираторными нарушениями.

В тактику лечения новорожденных с гипоксическиишемической энцефалопатией среднетяжелой и тяжелой степени внедрен метод индуцированной лечебной гипотермии, позволяющий обеспечить им нейропротективный эффект.

Наиболее распространенной патологией $\mathrm{y}$ недоношенных с экстремально низкой и очень низкой массой, связанной с их незрелостью, является респираторный дистресс синдром (РДС), достаточно часто приводящий к летальному исходу. Основными причинами развития РДС у новорожденных является нарушение синтеза и экскреции сурфактанта, связанное с незрелостью легочной ткани. Не исключается также наличие врожденного качественного дефекта структуры сурфактанта.

Учитывая, что повышение выживаемости новорожденных с экстремально низкой и очень низкой массой тела при рождении зависит от эффективности профилактики РДС,ее следует начинать до рождения ребенка [2,3]. Всем женщинам, госпитализированным в ННЦМД с угрозой преждевременных родов до 34 недель гестации, назначается курс антенатальных стероидов. Повторный курс антенатальных стероидов проводится в тех случаях, если после первого курса прошло более 2-3 недель и гестационный возраст плода не превышает 33 недели. Преждевременные роды можно несколько отсрочить посредством назначения токолитиков и антибиотиков, в случае преждевременного разрыва плодных оболочек.

Антенатальный курс стероидов также назначается женщинам, у которых будет проводиться плановое кесарево сечение, до начала сократительной деятельности в связи с наступлением срока родов [4].

Недоношенные новорожденные с экстремально низкой и очень низкой массой тела при рождении наиболее часто нуждаются в реанимации. Поэтому очень важна должная подготовка при каждых преждевременных родах и обязательное наличие всего реанимационного оборудования.

В случае ожидаемых преждевременных родов температура воздуха в родильной палате повышается до $\geq 26^{\circ} \mathrm{C}$, предварительно включается источник лучистого тепла, чтобы обеспечить комфортную температуру окружающей среды для недоношенного новорожденного. Если ожидается рождение ребенка со сроком гестации менее 28 недель, готовится термостойкий пластиковый пакет или полиэтиленовая пленка пищевого или медицинского назначения. Кроме того, обеспечивается согревание и увлажнение газов, использующихся для стабилизации состояния новорожденного, что также может помочь поддержать температуру его тела[5,6]. Всегда должны быть в наличии пульсоксиметр и смеситель, присоединенный к источнику кислорода и сжатого воздухаВажно иметь подготовленный, предварительно согретый транспортный инкубатор для поддержания температуры тела новорожденного при его транспортировке в отделение интенсивной терапии после стабилизации в родильном зале.

В случае преждевременных родов в родильный зал 
вызывается команда неонатологов-реаниматологов из отделения реанимации и интенсивной терапии (ОРИТН), хорошо владеющих навыками интубации трахеи и экстренной катетеризации пупочной вены [7].

Недоношенные новорожденные с гестационным возрастом 28 недель и менее сразу же после рождения помещаются (без обсушивания) в полиэтиленовый пакет или под полиэтиленовую пеленку по шею и укладываются на заранее подогретые пеленки на реанимационном столе под источник лучистого тепла [8]. Поверхность головы ребенка дополнительно покрывается пленкой или шапочкой. Датчик пульсоксиметра присоединяется к правому запястью ребенка до его помещения в пакет. Пакет или пленка не убираются во время реанимационных мероприятий. Все реанимационные мероприятия, включая интубацию трахеи, непрямой массаж сердца, венозный доступ, осуществляются при одновременном мониторировании температуры тела новорожденного.

Известно,что у большинства недоношенных новорожденных нехарактерно апноэ при рождении [9]. В силу незрелости легких и дефицита сурфактанта у них затруднена естественная вентиляция легких и формирование их функциональной остаточной емкости (ФОЕ). Обеспечение контролируемого раннего СРАР (постоянного положительного давления в дыхательных путях) с возможностью проведения дополнительных контролируемых раздуваний при наличии самостоятельных дыханий, в настоящее время является основным способом безопасной стабилизации состояния недоношенных новорожденных сразу после рождения, снижающим потребность в механической вентиляции (MB) и терапии сурфактантом [10,11]. Во время обеспечения СРАР легкие новорожденного постоянно поддерживаются в слегка раздутом состоянии и он не прилагает большие усилия для повторного заполнения легких воздухом во время каждого выдоха.

Для начала стабилизации состояния недоношенного новорожденного СРАР целесообразно начинать с давления 5 см водн. ст. и концентрации кислорода 21-30\%, а ее повышение или снижение проводить на основании показаний пульсоксиметра, закрепленного на запястье правой руки с момента рождения для получения информации о ЧСС и сатурации (SpO2). После рождения сатурация повышается постепенно примерно с $60 \%$ до $80 \%$ в течение 5 минут, достигая 85\% и выше приблизительно к 10-й минуте [1214].

Если самостоятельное дыхание у ребенка отсутствует, вместо СРАР проводится принудительная вентиляция легких с использованием Т-коннектора, присоединенного к дыхательному аппарату, с частотой дыхания 40-60 вдохов в 1 минуту. При этом оптимальное давление на вдохе (PIP) в течение первых принудительных вдохов подбирается индивидуально для конкретного новорожденного до восстановления сердечного ритма и появления экскурсии грудной клетки. В течение всего времени принудительной вентиляции легких оцениваются попытки появления самостоятельного дыхания, ЧСС и сатурация крови кислородом непрерывно или через каждые 30 секунд

Интубацию трахеи в родильном зале проводим у младенцев, не ответивших на вентиляцию с положительным давлением через лицевую маску, при проведении непрямого массажа сердца, а также недоношенным с гестационным возрастом менее 26 недель для введения сурфактанта с заместительной целью и детям с врожденной диафрагмальной грыжей.

После того, как была налажена адекватная вентиляция легких и восстановлена ЧСС, новорожденный переводится в предварительно согретом транспортном кувезе в отделение интенсивной терапии, где осуществляться его обследование и лечение.

Недоношенный ребенок имеет очень небольшие запасы гликогена. В процессе реанимации его энергетические запасы истощаются, вследствие чего может развиться гипогликемия, являющаяся фактором риска поражения головного мозга и неблагоприятных исходов при наличии гипоксии или ишемии. Поэтому для предупреждения развития гипогликемии в первые 12 часов постреанимационного периода осуществляется внутривенное введение глюкозы с контролем ее уровня через каждые 3 часа.

У недоношенных детей продолжительное апноэ и выраженная брадикардия в постреанимационном периоде могут быть первыми клиническими признаками нарушений температурного баланса, насыщения крови кислородом, снижения уровня электролитов и глюкозы крови, наличия ацидоза, инфекции. Для предупреждения указанных нарушений необходим мониторинг и поддержание уровня глюкозы в пределах 2,6 - 5,5 ммоль/л; общего кальция 1,75 2,73 ммоль/л; натрия 134 - 146 мЭкв/л; калия 3,0 - 7,0 мЭкв/л.

Для обеспечения адекватной вентиляции легких и соответствующей концентрации кислорода, проводится контроль насыщения крови кислородом (SpO2) до тех пор, пока организм ребенка сможет поддерживать нормальную оксигенацию при дыхании воздухом.

У младенцев с апноэ, а также для облегчения прекращения механической вентиляции применяем кофеин, который также назначается всем младенцам с высоким риском необходимости МB, например, с массой при рождении менее 1250 г, которые находятся на неинвазивной вспомогательной искусственной вентиляции лёгких [15].

Для облегчения экстубации у младенцев, которые оставались на МВ в течение 1-2 недель, применяем короткий курс терапии дексаметазоном в низких или очень низких дозах, с постепенным снижением дозы.

Парентеральное питание начинаем с первого дня и быстро увеличиваем объем, начиная с 3.5 г/кг/день белка и 3.0 г/кг/день липидов, по мере их переносимости. Минимальное энтеральное питание сцеженным материнским молоком также начинаем с первого дня, начиная с 1 г [16-17].

Снижение системного кровотока и гипотензия могут быть связаны с гиповолемией, шунтированием крови слева направо через открытый артериальный проток или овальное окно, а также с дисфункцией миокарда. Установление причины поможет выбрать наиболее правильную тактику лечения. Ранняя гиповолемия может быть минимизирована путем отсрочки перевязки пуповины на 60 сек. с удерживанием ребенка ниже матери для содействия плаценто-плодовой трансфузии [18-19].

При гиповолемии, подтвержденной на эхокардиограмме, а также в том случае, если причина точно не установлена, следует рассмотреть возможность увеличения объема крови посредством введения 10-20 мл/ кг физиологического раствора, но не коллоида.

При лечении артериальной гипотензии у недоношенных детей допамин обладает большей эффективностью, по сравнению с добутамином, в отношении влияния на краткосрочные исходы [20], однако добутамин может быть более рациональным выбором при 
дисфункции миокарда и низком системном кровотоке. В случае неэффективности традиционного лечения артериальной гипотензии, может также использоваться гидрокортизон [21].

Наличие открытого артериального протока (ОАП) у глубоко недоношенных новорожденных с РДС может обусловить множество клинических проблем. Профилактическое введение индометацина способствует облитерации ОАП и уменьшению ВЖК. [22]. Индометацин или ибупрофен могут использоваться и при ранних признаках ОАП, таких как гипотензия (особенно при низком диастолическом давлении). Эффективность обоих препаратов идентична, хотя ибупрофен ассоциируется с более низкой степенью побочных эффектов со стороны почек [23].

Внедрение впрактику ОРИТН указанных выше доминирующих аспектов стабилизации состояния и выхаживания больных доношенных и недоношенных новорожденных способствовала улучшению основных показателей качества работы отделения.Так, за последние 10 лет через ОРИТН прошло 4067новорожденных в критическом состоянии. Из них новорожденных с экстремально низкой (500-999 г) $12.9 \%$ с очень низкой (1000-1499 г) 20.9\% и 18.3\% с массой тела 1500-2499г.

Выживаемость новорожденных за указанный период повысилась в весовой категории 500-999 г с 53\% до 84\%, $1000-1499$ г - с $78 \%$ до $93 \%$.

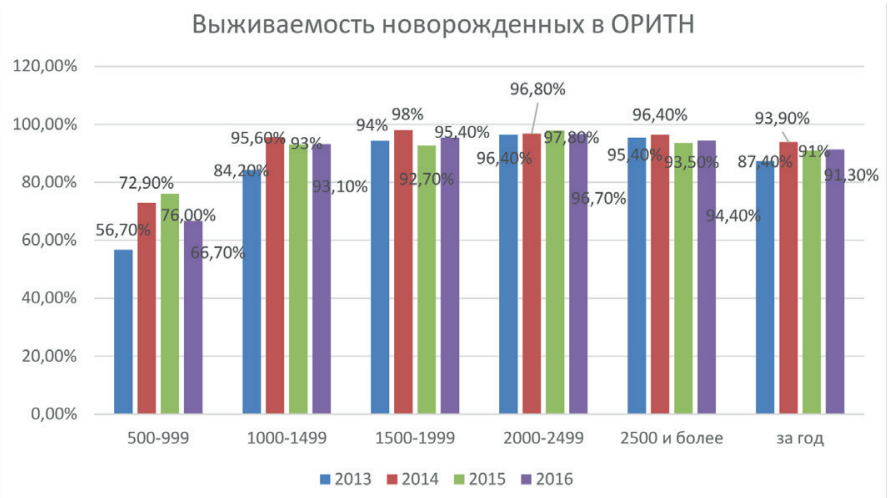

Рисунок 1 - Выживаемость новорожденных в зависимости от массы тела при рождении.
Причем, их выживаемость повысилась, несмотря на значительное повышение числа новорожденных с тяжелой хирургической патологией. В ННЦМД из регионов республики на роды госпитализируются беременные с тяжелыми врожденными аномалиями сердечно-сосудистой системы, органов пищеварения и др. у их плодов, которым после рождения проводится должная предоперационная подготовка и лечение. Оперативные вмешательства проводятся в кардиохирургическом центре и отделении неонатальной хирургии ННЦМД

При сравнении качественных показателей с ННЦМД с аналогичными в республиканских стационарах, выявлены более низкие показателей ранней и поздней неонатальной смертности и, в целом неонатальной смертности, а также постнеонатальной и младенческой смертности, чем в других республиканских организациях (см. рис 2).

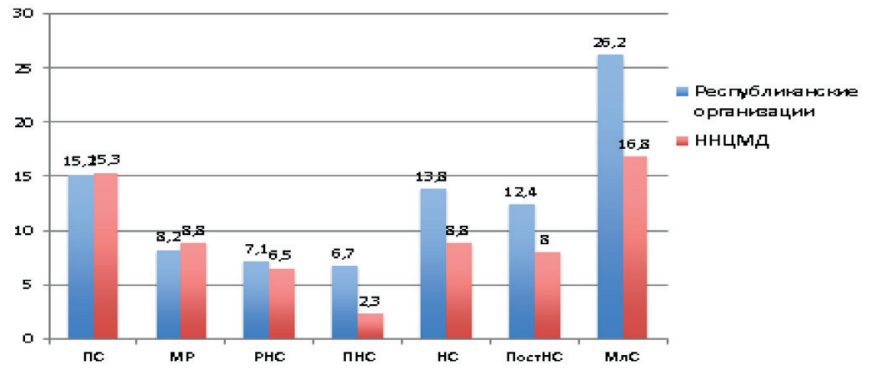

Рисунок 2 - Основные качественные показатели работы Республиканских организаций родовспоможения и ННЦМД.

Помимо работы непосредственно в отделениях, сотрудники ОРИТН оказывают организационнометодическую и консультативную помощь, проводят тематические тренинги для неонатологов регионов путем выезда непосредственно в родовспомогательные организации, или с использованием телевизионных связей (телемедицина). Кроме того, сотрудники отдела участвуют в проведении перинатального аудита, мониторинга и анализа критических состояний у новорожденных по регионам.

\section{Литература:}

1. Jackson JC. Adverse events associated with exchange transfusion in healthy and ill newborns. Pediatrics. 1997; 99:724-726.

2. Porto AM, Cjutinho IC, Correia JB, Amorin MM. Effectiveness of antenatal corticosteroids inreducing respiratory disorders in late preterm. Infants: randomized clinical trial. BMJ. 2011; 342: dl 696.

3. Crowther CA, McKinlay CJ, Middleton P, Harding JE. Repeat doses of prenatal corticosteroids for women at risk of preterm birth for improving neonatal health outcomes. Cochrane Database syst. 2011; 3:CD003935.

4. Sotiriadis A, Makrydimas G, Papatheodorou S, Ioannidis JP. Corticosteroids for preventing neonatal respiratory morbidity after elective caesarean section at term. Cochrane Database syst.2009; 3:CD006614.

5. Te Pas A.B., Lopriore E, Dito I, Morley CJ, Walther F.J. Humidified and heated air during stabilization at birth improves temperature in preterm infants. Pediatrics. 2010; 125:1427-1432.

6. McCarthy LK,Hensey CC, O'Donnell CP. In vitro effect of exzothermic mattresses on temperature in the delivery room Resuscitation. 2012; 201-202.

7. Kattwinkel J, Perlman JM, Aziz K, Colby C, et all. Neonatal resuscitation. 2010.

8. McCall EM, Alderdice F, Halliday HI, Jenkins JG, Vohra S. Interventions to prevent hypothermia at birth in preterm and/or low birthweight infants. Cochrane Database syst. 2010; CD004210.

9. European Consensus Guidelines on Management of neonatal Respiratory Distress Syndrome in preterm infants - 2013 Update Consensus Guidelines. 
10. Finner NN, Carlo WA, Walsh MC, Rich W, Ganttz MG, Yoder BA, et all: Early CPAP versus surfactant in extremely preterm infants. N Engl. J. Med. 2010;362:1970-1979.

11. 11. O'Donnell CP, Schmolzer GM. Resuscitation of preterm infants: delivery room interventions and their effect on outcomes. Clin. Perinatol. 2012; 39: 875-869.

12. Finer N, Leone T. Oxygen saturation monitoring for the preterm infant: the evidence basis for current practice. Pediatr. 2009; 65:375-380.

13. Kamlin CO, O’Donnell CP, Davis PG, Morley CJ. Oxygen saturation in healthy infants immediately after birth. Pediatr. 2006; 148:585-589.

14. Saugstad O.D., Ramji S., Soll R.F., Vento M. Resuscitation of newborn infants with 21 or $100 \%$ oxygen: an updated systematic review and meta-analysis. Neonatology. 2008; 94: 176-182.

15. Schmidt B, Andersen PJ, Doyle LW, Dewey D, et all. Caffeine for Apnea of Prematurity (CPAP) treal investigations: Survival without disability to age 5 years afther neonatal caffeine therapy for apnea of prematurity. JAMA. 2012;307:275-282.

16. Hay WW Jr. Strategies for feeding the preterm infant. Neonatology. 2008; 94:245-254.

17. Ehrenkranz RA. Early, aggressive nutritional management for very low birth weight infants: what is the evidence? Semin. Perinatol. 2007; 31:48-55.

18. Rabe H., Reynolds G., Diaz-Rossello J. A systematic review and meta-analysis of a brief delay in clamping the umbilical cord of preterm infants. Neonatology. 2008; 93:138-144.

19. Committee on Obstetric Practice, American College of Obstetricians and Gynecol. 2012;120:1522-1526.

20. Subhedar NV, Shaw NJ. Dopamine versus dobutamine for hypotensive preterm infants. Cochrane Database Syst. 2003;2 :CD001242.

21. Ibrahim H, Sinha IP, Subhedar NV. Corticosteroids for treating hypotension in preterm infants. Cochrane Database Syst. 2011; CD003662.

22. Ohlsson A, Walia R, Shah S. Ibuprofen for the treatment of patent ductus arteriosus in preterm andlor low birth weight infants. Cochrane Database Syst. 2008;1:CD003481.

23. Neumann R, Schulzke SM, Buhrer C. Oral ibuprofen versus intravenous ibuprofen or intravenous indomethacin for treatment of patent ductus arteriosus in preterm infants: a systematic review and meta-analysis. Neonatology. 2012; 102:9-15. 